\title{
Interhospital Transportation of Mass Burn Casualties
}

\author{
Sabine M. van Harten ${ }^{1}$, Lieke Welling ${ }^{2}$, Roberto S. G. M. Perez ${ }^{3}$, Peter Patka ${ }^{4}$, Pieter Henny ${ }^{5}$, \\ Robert W. Kreis ${ }^{6}$
}

\begin{abstract}
Aim of Study: To establish the impact of the transportation on the condition and outcome of the victims of the Volendam fire incident.

Methods: Medical and logistic parameters from all victims in the Intensive Care Unit (ICU) were retrospectively collected. Physiologic parameters in the first $24 \mathrm{~h}$ and outcome parameters were compared between the transported and the non-transported patients.

Results: The first 24 h, 105 patients were admitted to an ICU: 47 of them were relocated during that same day. The $\mathrm{pH}$ value was significantly lower in the transported group $(p=0.016)$. Systolic blood pressure, bicarbonate, carbon dioxide, temperature, APACHE II score and fluctuation during the first day, as well as condition during the second day did not differ significantly. The origin of the acidosis seemed to be mainly metabolic. The number of hospitalization days was larger in the transported group with severe burn injury ( $\geq 25 \%$ total body surface area burnt), comparing to the non-transported group $(p=0.015)$. Ventilation days and mortality did not differ significantly. Conclusions: The transported patients had a lower $\mathrm{pH}$ the first day after transportation, but condition during the second day as well as ventilation day and mortality did not differ between the transported and the non-transported group. Therefore, transportation during the unstable phase, the first day post-burn,
\end{abstract}

seemed not to have had a negative impact on patient outcome.

\author{
Key Words \\ Burns - Disaster - Transportation \\ Eur J Trauma Emerg Surg 2007;33:176-182 \\ DOI 10.1007/s00068-007-5131-z
}

\section{Introduction}

Several strategies are available for distribution of victims of mass burn incidents. Depending on the availability of transport, victims are quickly removed from the scene and brought to the nearest hospitals for stabilization (scoop and run). Subsequently, a secondary distribution or interhospital transportation is often needed, as was the case after the Ramstein disaster [1]. Another strategy is to stabilize the victims at the scene (stay and play) and bring them directly to the appropriate hospital, thereby often preventing the need for secondary distribution [2]. No consensus seems to exist with respect to primary treatment, transportation and secondary distribution of mass burn victims. Transportation of critically ill patients is often deemed unsafe because of medical instability [3-6]. After the Volendam café fire on New Years Eve 2000, patients were brought to the nearest hospitals as soon as

\footnotetext{
'Department of Surgery, Zaans Medical Center, Zaandam,

The Netherlands,

${ }^{2}$ Department of Surgery, Academic Medical Center, Amsterdam, The Netherlands,

${ }^{3}$ Department of Anaesthesiology, VU University Medical Center, Amsterdam, The Netherlands,

${ }^{4}$ Department of Surgery, Erasmus Medical Center, Rotterdam, The Netherlands,

${ }^{5}$ Department of Anaesthesiology, Academic Medical Center, Amsterdam, The Netherlands,

${ }^{6}$ Burns Center, Red Cross Hospital, Beverwijk, The Netherlands.
} 
possible. Subsequently, secondary distribution of the severely injured patients took place by ambulance or helicopter transport. Most patients were transported within $24 \mathrm{~h}$, which is a phase of medical instability for severely burned patients [7-10]. However, these early transports were inevitable due to a shortage of Intensive Care Unit (ICU) beds or the need for specific treatment.

The aim of this study was to establish the impact of the interhospital transportation of the severely injured patients on their condition and outcome and to determine the influence of the different modes of transport.

\section{Materials and Methods}

\section{Setting of the Accident}

On New Years Eve 2000, a fire broke out in a café in Volendam, The Netherlands. A total of 245 young people were injured, 182 of whom required hospitalization. Soon after the fire, a multidisciplinary group was founded by the Traumacentrum Noord-West Nederland (Northwest Netherlands Trauma Center) to investigate all medical aspects of the disaster. The course of the fire and the following care process has been described elsewhere [11-13]. This study focuses on the secondary distribution.

\section{Redistribution}

A few hours after the fire, two specialized teams - each consisting of at least two experienced burn physicians (burn teams) - were formed by the nearest burn centers. They visited the hospitals to make an inventory of the number of burn patients and the severity of their injuries to establish which patients would benefit most from treatment in a burn center. Criteria for admission to a burn center in The Netherlands are adopted from the Emergency Management of Severe Burns protocol $\left(\mathrm{EMSB}^{\circledR}\right)$ [14]. Under normal circumstances patients with a Total Body Surface Area burnt (TBSA) of more than $10 \%$ are generally admitted to a burn center. Because of the large number of victims who met the formal criteria, the burn teams adapted the criteria to this situation of high demand, in order to cope with the limited availability of specialized hospital resources. Patients with burns $<30 \%$ TBSA could stay in smaller (rural area) hospitals. Patients with less than 30\% TBSA and an inhalation trauma could be treated in a university center or large hospital. The criteria for admission to a burn center were raised from $\geq 10 \%$ TBSA to $\geq 30 \%$ TBSA and the presence of an inhalation trauma. Even after adaptation of the criteria, the capacity of the Dutch burn centers was not sufficient to treat all severely burned patients. Therefore, Belgian and German burn centers were requested to assist. Soon after the fire, patients were redistributed and transferred to different hospitals by either ambulance or helicopter.

Initially, 20 hospitals received casualties (1 burn center, 4 university centers and 15 rural area hospitals). After secondary distribution, 33 hospitals were involved ( 8 international burn centers, 3 national burn centers, 17 rural area hospitals and 5 university centers) Before secondary distribution, $60(57 \%)$ patients were in the ICU of a rural area hospital, $42(40 \%)$ patients were in the ICU of an university center, and three patients were brought directly to a burn center. After 2 days, $29(28 \%)$ patients were admitted to an ICU of a rural area hospital, 37 (35\%) patients to the ICU of a university center and $39(37 \%)$ to a burn center. The influence of adjusted burn center referral criteria on primary outcome will be reported elsewhere.

All burn victims who were admitted to an ICU during the first $24 \mathrm{~h}$ post-burn were included in the present study. A number of physiological parameters on the first and second day of admission were gathered retrospectively, as well as patient outcome parameters and logistic parameters concerning the time and mode of transport. Case Report Forms were developed to ensure standardized data-collection. Data were obtained from hospital medical records and ambulance transfer reports. The chart review was conducted by trained research assistants. The following physiological parameters were used as an indication of the patient's condition: lowest systolic blood pressure, $\mathrm{pH}$ of the blood and central temperature during the first and second day in the ICU. The lowest actual bicarbonate $\left[\mathrm{HCO}_{3}(\mathrm{mmol} / \mathrm{l})\right]$ and highest carbon dioxide $\left[\mathrm{CO}_{2}\right.$ $(\mathrm{mmHg})]$ were used to determine the nature of the acidosis. As an overall score for condition in the first $24 \mathrm{~h}$ the Acute Physiology and Chronic Health Evaluation (APACHE) II score was used [15]. Fluctuation in physiologic parameters was determined by the absolute differences between the highest and the lowest values of $\mathrm{pH}$, temperature and systolic blood pressure. This was established for all patients in the ICU during the first and second day and for the transported patients during transport as well. Patient outcome was defined by ventilation days, hospital admission time and mortality. The occurrences of the following major complications were scored: Systemic Inflammatory Response Syndrome (SIRS), Acute Respiratory Distress Syndrome (ARDS), failure of one or more organs, a period of severe hemodynamic instability or Disseminated Intravascular Coagulation (DIC). Definitions were accepted as recorded. 


\section{Statistical Analysis}

Patient and trauma parameters are described as means \pm SD or medians and interquartile ranges if not normally distributed. Prognostic comparability of both groups was checked using the Chi-square test in case of binomial parameters, Student $t$ test in case of a normal distribution and Mann-Whitney U test when parameters where not normally distributed. Differences in physiological and outcome parameters between the transported and the non-transported group were analyzed using analysis of variance (ANOVA) in case of a normal distribution. The influence of the confounding variables on the patient's condition was included in the model. In order to control for the influence of confounding variables with not normally distributed data, separate subgroup analysis for confounding variables were performed using the Mann-Whitney $U$ test or Chi-square test. Statistical analysis was performed using SPSS 11.0 software package (SPSS ${ }^{\circledR}$ Inc., Chicago, IL, USA). Significances were accepted at $\mathrm{p}<0.05$.

\section{Correction for Confounding}

The groups of transported and non-transported patients were compared to establish any differences in sustained injury and demographics. Burn injury was expressed as \% TBSA. Inhalation injury was defined as the necessity of artificial ventilation for more than $24 \mathrm{~h}$.

Both TBSA and age were found to be significantly different in the transported and the non-transported group who were in the ICU the first day post-burn (Table 1). As the minor age difference between transported and non-transported groups was considered not clinically relevant, analyses were not corrected for the influence of age. The possible influence of TBSA on the patient's condition and outcome was accounted for in our statistic models where appropriate.

For severity of burn injury the group was divided in patients with $<25 \%$ TBSA and those with $\geq 25 \%$ TBSA, based on the median of TBSA in the entire group. The influence of TBSA on the physiologic parameters on the first day in the ICU was established. A significant difference was found in $\mathrm{pH}(\mathrm{p}<0.001)$, actual bicarbonate $(\mathrm{p}<0.001$, carbon dioxide $(\mathrm{p}<0.05)$, temperature $(\mathrm{p}<0.001)$, systolic blood pressure $(\mathrm{p}<0.001)$ and APACHE II-score $(\mathrm{p}<0.001)$ between the two groups of high and low TBSA. Additionally, the influence of TBSA on the fluctuation in physiologic parameters during the first day in ICU was established. There was a significant difference in fluctuation of the systolic blood pressure $(\mathrm{p}<0.001)$ and $\mathrm{pH}(\mathrm{p}<0.001)$
Table 1. Demographic data and injury, first day in ICU $(N=105)$.

\begin{tabular}{|c|c|c|c|}
\hline & No transport & Transport & $\mathrm{p}$ value \\
\hline Number of patients & 58 & 47 & \\
\hline Age $\left(\right.$ years) ${ }^{\mathrm{a}}$ & $17.5 \pm 2.5$ & $16.3 \pm 2.3$ & $0.019^{c f}$ \\
\hline Gender: male & 41 & 28 & $0.324^{\mathrm{d}}$ \\
\hline Inhalation injury & 47 & 44 & $0.11^{d}$ \\
\hline TBSA $\%^{\mathrm{b}}$ & $14.5(8-30)$ & $36(24-51)$ & $<0.001^{\mathrm{ef}}$ \\
\hline
\end{tabular}

${ }^{\text {a }}$ Mean $\pm S D$

${ }^{\mathrm{b}}$ Median (IOR)

c Student $\mathrm{t}$

${ }^{d}$ Chi-square

e Mann-Whitney U

f Significant $(p<0.05)$

during the day between the two different TBSA groups, whereas the fluctuation of temperature was not significantly different $(p=0.095)$. Finally the influence of TBSA on the outcome parameters was established. TBSA had a significant influence on hospitalization days $(\mathrm{p}<0.001)$, ventilation days $(\mathrm{p}<0.001)$ and mortality $(\mathrm{p}<0.05)$.

The same was done for the second day in the ICU. The groups of transported $(n=44)$ and non-transported patients $(n=51)$ who were still in the ICU on the second day were compared to establish any differences in sustained injury and demographics. Only TBSA was found to be significantly different in the transported and the non-transported group. TBSA had a significant influence on $\mathrm{pH}(\mathrm{p}<0.001)$, temperature $(\mathrm{p}<0.05)$ and systolic blood pressure $(\mathrm{p}<0.001)$, as well as on the fluctuation of $\mathrm{pH}(\mathrm{p}<0.05$, temperature $(\mathrm{p}<0.001)$ and systolic blood pressure $(\mathrm{p}<0.05)$ the second day in ICU.

\section{Results \\ Patients}

The first $24 \mathrm{~h}$ (post-burn day 0), 105 patients were admitted to an ICU. During that same day 47 patients were transported and 58 were not. Table 1 shows the demographic data and sustained injuries of both groups. There was a significant difference in mean age $(\mathrm{p}<0.05)$ and median TBSA $(\mathrm{p}<0.001)$ between the transported and the non-transported group. No significant differences were found in gender $(p=0.32)$ and presence of inhalation injury $(\mathrm{p}=0.11)$. The influence of the confounding variables on the patient's condition and outcome parameters are described in the Materials and Methods section. The results described in the results section are adjusted data. 
Table 2. Condition, first day in ICU ( $\mathrm{N}=105)$, adjusted data.

\begin{tabular}{llll}
\hline & No transport $=\mathbf{5 8}$ & Transport $\mathbf{n}=\mathbf{4 7}$ & p value \\
\hline $\mathrm{pH}^{\mathrm{a}}$ & $7.30 \pm 0.10$ & $7.23 \pm 0.07$ & $0.016^{\mathrm{b}}$ \\
$\mathrm{HCO}_{3}{ }^{\mathrm{a}}$ & $20.2 \pm 6.8$ & $16.4 \pm 3.8$ & 0.878 \\
$\mathrm{CO}_{2}{ }^{\mathrm{a}}$ & $44.0 \pm 8.3$ & $46.5 \pm 7.6$ & 0.411 \\
Temperature $^{\mathrm{a}}$ & $35.8 \pm 1.8$ & $35.3 \pm 2.1$ & 0.285 \\
Systolic RR $^{\mathrm{a}}$ & $94 \pm 18$ & $75 \pm 16$ & 0.174 \\
APACHE II score $^{\mathrm{a}}$ & $12 \pm 5$ & $16 \pm 4$ & 0.443 \\
\hline
\end{tabular}

${ }^{a}$ Mean \pm SD $(n)$

${ }^{b}$ Significant $(p<0.05)$

Table 3. Fluctuation of physiological parameters, first day in ICU $(\mathrm{N}=105)$, adjusted data.

\begin{tabular}{llll}
\hline & No transport $(\mathbf{n}=\mathbf{5 8})$ & Transport $(\mathbf{n}=\mathbf{4 7})$ & $\mathbf{p}$ value \\
\hline $\mathrm{pH}^{\mathrm{a}}$ & $0.11 \pm 0.09$ & $0.18 \pm 0.12$ & 0.744 \\
Temperature $^{\mathrm{a}}$ & $2.5 \pm 1.7$ & $2.8 \pm 1.8$ & 0.916 \\
Systolic RR $^{\mathrm{a}}$ & $59 \pm 30$ & $79 \pm 32$ & 0.114 \\
\hline
\end{tabular}

${ }^{\text {a }}$ Mean absolute differences \pm SD $(n)$

\section{Condition: First Day in ICU}

With correction for the confounder TBSA, analysis of variance was performed to determine the influence of transport on the patient's condition during the first day in the ICU. A significant difference was found in $\mathrm{pH}$ $(p<0.05)$ between the transported and the nontransported group. No significant difference was found in actual bicarbonate $(\mathrm{p}=0.878)$, carbon dioxide $(\mathrm{p}=0.411)$, systolic blood pressure $(\mathrm{p}=0.174)$, temperature $(\mathrm{p}=0.285)$ and APACHE II-score $(\mathrm{p}=0.443)($ Table 2$)$.

\section{Fluctuation: First Day in ICU}

Analysis of variance was performed, again with correction for the confounder TBSA, to determine the influence of transport on the fluctuation of the physiologic parameters during the day. No significant difference was found in fluctuation of the systolic blood pressure $(\mathrm{p}=0.114)$, temperature $(\mathrm{p}=0.916)$ or $\mathrm{pH}$ $(\mathrm{p}=0.744)$ between the transported and the nontransported group (Table 3 ).

\section{Condition and Fluctuation: Second Day in ICU}

The condition and fluctuation in physiologic parameters on the second day in the ICU were established for those patients who were transported the first day and were still in the ICU on the second day $(n=44)$. These were compared to the same parameters in the patients who were not transported and were still in the ICU on the second day $(\mathrm{n}=51)$. One confounder (TBSA) was included in the model. Analysis of variance revealed no significant differences in systolic blood pressure $(\mathrm{p}=0.24)$, temperature $(\mathrm{p}=0.21)$ and $\mathrm{pH}(\mathrm{p}=0.86)$ on the second day in the ICU between the transported and the non-transported group. Fluctuation in physiologic parameters on the second day in ICU was not significantly different in the two groups [systolic blood pressure $(\mathrm{p}=0.53)$, temperature $(\mathrm{p}=0.27)$ and $\mathrm{pH}$ $(\mathrm{p}=0.5)]$.

\section{Outcome Parameters}

There was no difference in the incidence of major complications (SIRS, ARDS, failure of one or more organs, severe hemodynamic instability and DIC) between the transported and the non-transported patients $(p=0.27)$. The number of hospitalization days was significantly higher for the transported compared to the non-transported group $(\mathrm{p}<0.05)$ in patients with a high TBSA. No significant differences were found in either subgroups for ventilation days (low TBSA: $p=0.361$; high TBSA: $p=0.274$ ) and mortality (low TBSA: not available; high TBSA: $p=0.507$ ) between the transported and non-transported patients (Table 4).

The transported patients in the high TBSA group who were transported to a foreign hospital $(\mathrm{n}=18)$ were hospitalized longer [median hospitalization days 85 (IQR 48-134)] comparing to the patients who were transported to national hospitals $(\mathrm{n}=29)$ [median 48 (IQR 26-107)].

\section{Mode of Transport}

In the course of the first $24 \mathrm{~h}, 35$ ICU patients were transported by ambulance and 12 by helicopter. Demographic data, injury and logistic parameters of these two groups are shown in Table 5.

There was a significant difference in transportation distance $(\mathrm{p}<0.001)$, but not in duration of the transport $(p=0.117)$. The duration was calculated from the time of departure from the sending hospital to the time of arrival at the receiving hospital. This included the transfer time to and from the transport vehicle. A significant difference in age was found between the two groups $(p<0.05)$. Injury severity and gender were not significantly different.

\section{Discussion}

After the Volendam café fire the large number of severely injured patients led to overcrowding of the 
Table 4. Outcome parameters $(\mathrm{N}=105)$, in subgroups for high and low total body surface area burnt (TBSA).

\begin{tabular}{|c|c|c|c|c|}
\hline & & No transport $(n=44)$ & Transport $(n=14)$ & $\mathrm{p}$ value \\
\hline \multirow[t]{4}{*}{ TBSA $<25 \%$} & Hospitalization days $^{\mathrm{a}}$ & $24(10-31)$ & $28(25-39)$ & $0.102^{\mathrm{b}}$ \\
\hline & Ventilation days $^{a}$ & $8(1-16)$ & $10(5-17)$ & $0.361^{\mathrm{b}}$ \\
\hline & Mortality & 0 & 0 & - \\
\hline & & No transport $(n=14)$ & Transport $(n=33)$ & $p$ value \\
\hline \multirow[t]{3}{*}{ TBSA $\geq 25 \%$} & Hospitalization days $^{\mathrm{a}}$ & $36(18-73)$ & $89(55-131)$ & $0.015^{\mathrm{bd}}$ \\
\hline & Ventilation days $^{\mathrm{a}}$ & $23(3-29)$ & $20(10-40)$ & $0.274^{\mathrm{b}}$ \\
\hline & Mortality & 4 & 5 & $0.507^{c}$ \\
\hline
\end{tabular}

${ }^{a}$ Median (IOR)

b Mann-Whitney U

${ }^{c}$ Chi-square

d Significant $(p<0.05)$

Table 5. Demographic data of the transported patients $(n=47)$.

\begin{tabular}{|c|c|c|c|}
\hline & $\begin{array}{l}\text { Ambulance } \\
(\mathrm{n}=35)\end{array}$ & $\begin{array}{l}\text { Helicopter } \\
(\mathrm{n}=12)\end{array}$ & $\mathrm{p}$ value \\
\hline Age (years) ${ }^{a}$ & $16.8 \pm 2.5$ & $15.2 \pm 1.3$ & $0.037^{\mathrm{cf}}$ \\
\hline Gender: male & 22 & 6 & $0.658^{d}$ \\
\hline Inhalation injury & 32 & 12 & $0.716^{\mathrm{d}}$ \\
\hline TBSA $\%^{\mathrm{b}}$ & $34(18-51)$ & $45(35-53)$ & $0.118^{\mathrm{e}}$ \\
\hline Distance $(\mathrm{km})^{\mathrm{a}}$ & $116 \pm 74$ & $218 \pm 20$ & $<0.001^{\mathrm{cf}}$ \\
\hline Duration (min) ${ }^{a}$ & $133 \pm 96$ & $177 \pm 93$ & $0.117^{c}$ \\
\hline
\end{tabular}

${ }^{a}$ Mean \pm SD

${ }^{b}$ Median (IQR)

c Student $\mathrm{t}$

${ }^{d}$ Chi-square

e Mann-Whitney U

${ }^{f}$ Significant $(p<0.05)$

surrounding hospitals and a lack of ICU beds. Rapid secondary transportation was made possible by the burn teams who performed secondary triage just a few hours after the fire and developed a redistribution plan. Many victims fitted the criteria for admission to a specialized center even after adaptation of the criteria. This led to a great number of transfers between hospitals within the country as well as transfers to hospitals in both Belgium and Germany, starting a few hours after the fire. The best time of transportation of a burned patient has been discussed. Although burn patients can be hemodynamically unstable during the resuscitation phase (the first $48 \mathrm{~h}$ ), most authors agree that transporting the patient during this period is reasonable when it is clearly in the patient's interest [7-10, 16]. After the Volendam fire, most patients were transported during the first day, and a small number was transferred during the second day. After this period several patients were transferred or re-allocated, sometimes for social reasons or repatriation.

Significant differences were found in condition of the patients in the ICU during the first day between the transported and the non-transported group. Analysis revealed that these differences could be attributed entirely to the difference in TBSA and to the lesser extent to age differences between the groups. An exception was found for $\mathrm{pH}$, which remained lower in the transported group when controlled for the modifying influence of TBSA. On the second day no differences between the two groups could be identified anymore. Fluctuation in physiologic parameters was present in all patients during the first day post-burn. It was significantly more pronounced in patients with severe burn injury (TBSA $\geq 25 \%$ ), but no differences were found between the transported and the nontransported group. In addition several patient outcome parameters where compared between the transported and the non-transported group. A significant difference was found in hospitalization days between the transported and the non-transported patients in the group with severe burn injury (TBSA $\geq 25 \%$ ). This might be explained by the fact that more then one-third of the transported patients was treated in a burn center in Belgium or Germany. Many of these patients remained in these centers for rehabilitation. Also, in some cases repatriation was protracted due to the protocollary isolation of patients from foreign hospitals, who were suspected of colonization with methicillin-resistant Staphylococcus Aureus (MRSA) [17]. No significant difference was found in ventilation days and mortality. 
The majority of the burn victims received their first treatment in one of the regional hospitals located in the immediate surrounding of the fire area. This is in agreement with the national burn management guidelines, according to which patients are first brought to the surrounding hospitals for triage and initial treatment before referral to a burn center when necessary.

If a severely injured patient has to be transported, careful planning and preparation is of the utmost importance $[3,18]$. Medical team composition and level of training can also be important factors in outcome [6, 9, 19, 20]. Previous studies demonstrated that patients required several medical interventions prior and during transportation $[6,9]$. Lack of documentation is a common problem in disaster evaluation studies [21]. In this study no information could be found concerning interventions and problems during transport. Exchange of information may have taken place mouth-to-mouth or registration forms may have been lost. Several guidelines exist for the transfer of patients including the registration of a number of vital parameters prior and during transport $[5,7,15,22]$. This can be helpful in the exchange of patient information and in evaluating the clinical course during and after transportation.

As a measure for condition of the patient we used $\mathrm{pH}$, temperature and systolic blood pressure, which are used in the APACHE II score as indicators for the patient's condition.

The only difference found between the transported and the non-transported group was a lower $\mathrm{pH}$ on the first day in the transported group. Both metabolic and respiratory components can be the nature of this disturbance. No significant difference was found in actual bicarbonate and carbon dioxide between the transported and the non-transported groups. However, the data presented seem to point to a metabolic origin of the acidosis (low $\mathrm{pH}$ ). The actual bicarbonate is low in the transported group, whereas the carbon dioxide is within normal ranges. Patients possibly received less fluids before or during transport. A study in which the arterial blood gases of 19 victims who were transferred to a Belgian burn center were evaluated also revealed a mainly metabolic component to the acidosis [23]. Several other variables could have influenced the physiological disturbances during the first day in the ICU. For example: the treatment at the scene, the delay between the fire and the presentation of the patients in the hospitals and the treatment in the Emergency Department. However, insufficient data was available to be able to determine the influence of these variables. After the first day no differences were found between the transported and the non-trans- ported group. The specialized care given to the transported patients in the burn centers might have had an influence on the parameters and outcome.

Although we found a statistically significant difference of age between transported and non-transported patients, it is unlikely that this minor age difference will be of clinical relevance considering the young age and the uniform age distribution of these victims. Therefore, age was not incorporated as a confounder in the analysis. Although ideal circumstances for transportation have been outlined, in situations of overcrowding of hospitals and the need for specialized beds, the transportation of unstable patients seems to be safe. We did not find a negative influence of transport on the longer term.

Ambulances and several types of helicopters, both national and international were used for the transfers. When deciding which mode of transport is the best option, several considerations should be taken into account. The severity of injury, the distance to the receiving hospital and the possibilities for treatment during transport are but a few of them [19, 24-27]. In The Netherlands, distances rarely are an issue, since the country is small and most hospitals are easily reachable by ground ambulance. Therefore, in normal situations helicopter transport is seldom used. After the Volendam disaster several patients were transferred to Belgian hospitals by Belgian helicopters. However, in several cases there were problems adapting the Dutch equipment to the Belgian systems used in these helicopters [17]. Although the distance of transportation was significantly longer for the helicopter transports as compared to the ambulance transports, the duration of transport was not. Concerning international transports, it should be realized that systems might differ and that certain equipment cannot be adapted.

\section{Conclusions}

This study retrospectively reviewed the condition and outcome of the victims of the café fire in Volendam who were transported on the first day post-burn as compared to those who were not. No significant difference was found in condition during the first day except for a lower $\mathrm{pH}$ in the transported patients. Also a difference in hospitalization days was found between the transported and the non-transported patients. This might be explained by logistical problems concerning the repatriation of patients in foreign hospitals. Fluctuation of physiologic parameters during the first day in the ICU, condition during the second day as well as ventilation days and mortality did not differ between 
the transported and the non-transported group. Therefore, transportation during the unstable phase, the first day post-burn, seemed not to have had a negative impact on patient outcome.

\section{References}

1. Martin TE. The Ramstein airshow disaster. J R Army Med Corps 1990;136:19-26.

2. Arturson G. The Los Alfaques disaster: a boiling-liquid, expanding-vapour explosion. Burns 1981;7:233-51.

3. Fromm RE Jr, Dellinger RP. Transport of critically ill patients. J Intensive Care Med 1992;7:223-33.

4. Gebremichael M, Borg U, Habashi NM, et al. Interhospital transport of the extremely ill patient: the mobile intensive care unit. Crit Care Med 2000;28:79-85.

5. Guidelines Committee, American College of Critical Care Medicine, Society of Critical Care Medicine and the Transfer Guidelines Task Force Guidelines for the transfer of critically ill patients. Am J Crit Care 1993;2:189-95.

6. Martin GD, Cogbill TH, Landercasper J, Strutt PJ. Prospective analysis of rural interhospital transfer of injured patients to a referral trauma center. J Trauma 1990;30:1014-9.

7. Ellis A, Rylah TA. Transfer of the thermally injured patient. Br J Hosp Med 1990;44:206-8.

8. Judkins KC. Aeromedical transfer of burned patients: a review with special reference to European civilian practice. Burns Incl Therm Inj 1988;14:171-9.

9. Treat RC, Sirinek KR, Levine BA, Pruitt BA Jr. Air evacuation of thermally injured patients: principles of treatment and results. J Trauma 1980;20:275-9.

10. Ulrich $D$, Noah EM, von Heimburg D, Pallua N. Life threatening burn injuries on holidays: problems of primary care, homeland referral and treatment at a domestic burn center. Burns 2001;27:277-82.

11. Welling L, Harten SM, Patka P, Bierens JJLM, et al. The café fire on New Year's Eve in Volendam, The Netherlands: description of events. Burns 2005;31:548-54.

12. Welling L, Harten SM, Patka P, Bierens JJLM, et al. Medical management after indoor fires, a review. Burns 2005;31(6), 673-8.

13. van Harten SM, Welling L, Perez SGM, Patka P, Kreis RW. Management of multiple burn casualties from the Volendam disaster in the Emergency Departments of general hospitals. Eur J Emerg Med 2005;12:270-4.

14. Australia and New Zealand Burn Association. Emergency Management Of Severe Burns (EMSB) course manual, Dutch Version 01/og ed. 1996.
15. Knaus WA, Draper EA, Wagner DP, Zimmerman JE. APACHE II: a severity of disease classification system. Crit Care Med 1985;13:818-29.

16. Hadjiiski O, Dimitrov D. First aid and transportation of burned patients during mass disasters. Am J Emerg Med 1996;14:613-4.

17. Inspectie voor de Gezondheidszorg. Evaluatie Cafébrand Volendam. Den Haag: 2001 (report).

18. Trunkey DD. Transporting the critically burned patient. Top Emerg Med 1981;3:21-4

19. Schneider C, Gomez M, Lee R. Evaluation of ground ambulance, rotor-wing, and fixed-wing aircraft services. Crit Care Clin 1992;8:533-64.

20. van Wijngaarden $M$, Kortbeek J, Lafreniere $R$, et al. Air ambulance trauma transport: a quality review. J Trauma 1996;41:26-31.

21. Lillibridge SR, Noji EK. The importance of medical records in disaster epidemiology research. J AHIMA 1992;63:137-8.

22. Edlich RF, Haynes BW, Larkham N, et al. Emergency Department treatment, triage and transfer protocols for the burn patient. JACEP 1978;7:152-8.

23. Pirson J, Degrave E. Aeromedical transfer to Belgium of severely burned patients during the initial days following the Volendam fire. Mil Med 2003;168:360-3.

24. Baack BR, Smoot EC III, Kucan JO, et al. Helicopter transport of the patient with acute burns. J Burn Care Rehabil 1991;12:229-33.

25. Boyd CR, Corse KM, Campbell RC. Emergency interhospital transport of the major trauma patient: air versus ground. J Trauma 1989;29:789-93.

26. De Wing MD, Curry T, Stephenson E, et al. Cost-effective use of helicopters for the transportation of patients with burn injuries. J Burn Care Rehabil 2000;21:535-40.

27. Etxebarría MJ, Serrano S, Ruiz Ribó D. Prospective application of risk scores in the interhospital transports of patients. Eur J Emerg Med 1998;5:13-7.

\section{Address for Correspondence}

Sabine M. van Harten, MD

Department of Surgery

Zaans Medical Center

Koningin Julianaplein 58

1502 DV Zaandam

The Netherlands

Phone (+31/75) 650-2911, Fax -2576

e-mail: svanharten@hotmail.com 